Check for updates

Cite this: RSC Adv., 2017, 7, 32076

Received 17th April 2017

Accepted 15th June 2017

DOI: $10.1039 / \mathrm{c} 7 \mathrm{ra0} 4329 \mathrm{e}$

rsc.li/rsc-advances

\section{Fenton pre-treatment of rice straw with citric acid as an iron chelate reagent for enhancing saccharification $\uparrow$}

\begin{abstract}
Tao Sheng, (1) t $^{\mathrm{a}}$ Lei Zhao, tac $^{\mathrm{ac}}$ Wen-Zong Liu, ${ }^{\star b}$ Ling-fang Gao ${ }^{\mathrm{b}}$ and Ai-Jie Wang (D) *ab
The Fenton reagent has recently been verified as being effective for lignocellulose pretreatment. However, the Fenton reaction can only work under acidic conditions, leading to severe environmental pollution and increasing the cost for sewage treatment. This has made identification of iron chelates that could enhance Fenton degradation under neutral conditions important. In this study, citric acid, a non-toxic polyhydroxy carboxylic acid, was introduced as an iron chelate in Fenton pre-treatment of rice straw. Results demonstrated that citric acid has the ability to (i) maintain the oxidation capacity of the Fenton reagent under near-neutral conditions, (ii) enhance the degradation of lignin and reduce the crystallinity of rice straw from 0.41 to 0.21 , (iii) promote the saccharification of rice straw (the maximum saccharification ratio of $35.7 \%$ was two-fold higher than that for the untreated rice straw), and (iv) elevate the maximum activity of $\beta$-glucosidase from $0.33 \mathrm{IU} \mathrm{mL} \mathrm{mL}^{-1}$ to $0.61 \mathrm{IU} \mathrm{mL} \mathrm{L}^{-1}$. Moreover, the effect of operational parameters such as $\mathrm{pH}$ and processing time on the saccharification of rice straw by Fenton pretreatment with and without citric acid has been demonstrated. The findings strongly support Fenton plus citric acid as an efficient and environmentally friendly lignocellulose pretreatment method.
\end{abstract}

\section{Introduction}

Lignocellulose is one of the most abundant forms of biomass on the earth and is regarded as an ideal resource for bioenergy production in an era of fossil fuel deficiency. In China alone, the annual rice straw yield ranges between 180 and 270 million tons, ${ }^{1}$ but this large amount of resource is not ready to use because the highly crystalline structure and lignin bundles that make up $15-30 \%$ of the lignocellulose usually induce low cellulolytic activity and slow specific growth rates of the microorganisms involved. Therefore, an efficient pretreatment method is needed to remove the lignin and make the holocellulose (cellulose and hemicellulose) embedded in lignocellulose more accessible. This would allow enzymes or microorganisms to saccharify lignocellulose into sugars that can be further fermented to produce biofuel. Current pretreatment methods for lignin removal and structure decomposition are mainly focused on the use of dilute acid, ionic liquid,

${ }^{a}$ State Key Lab of Urban Water Resource and Environment, Harbin Institute of Technology, Harbin 150090, China.E-mail: waj0578@hit.edu.cn

${ }^{b}$ CAS Key Laboratory of Environmental Biotechnology, Research Center for EcoEnvironmental Sciences, Chinese Academy of Sciences, Beijing, China

${ }^{c}$ Advanced Water Management Centre, Faculty of Engineering, Architecture and Information Technology, The University of Queensland, Brisbane, QLD 4072, Australia $\uparrow$ Electronic supplementary information (ESI) available. See DOI: 10.1039/c7ra04329e

\$ These authors contributed equally to this work. microwave, hydrothermolysis, and stream explosion pretreatment. During the pretreatment process, high energy and pressure are usually required, thus leading to additional cost for corrosion-resistant and high-pressure reactors. ${ }^{2}$ Moreover, in the course of pretreatment, a great deal of inhibitors are produced, ${ }^{3}$ combined with substantial holocellulose loss, which will hinder the following saccharification and biofuel fermentation processes. ${ }^{4}$ Faced with these problems, biological pretreatment of lignocellulose has attracted much more attention due to characteristics such as environmental friendliness, high holocellulose reservation, and lack of inhibitor production. The only drawback of this method is its low pretreatment efficiency. ${ }^{5,6}$

Fenton pretreatment, the reaction mechanism of which is just like lignin degradation by fungi, has been verified as an ideal method that can improve the pretreatment efficiency while preserving the advantages of bio-pretreatment., Although typical Fenton was effective in the pretreatment of lignocellulose, low $\mathrm{pH}$ conditions $(\mathrm{pH}<4)$ were required to prevent the precipitation of iron. ${ }^{9}$ However, low $\mathrm{pH}$ is not only toxic to the subsequent bioprocesses, but, if the pretreatment residues were discharged to the environment, could also result in changes in food webs ${ }^{\mathbf{1 0}}$ and corrosion of sewage pipes. ${ }^{\mathbf{1 1}}$ The Fenton reaction can be performed at neutral $\mathrm{pH}$ in two different modes: homogenous and heterogeneous. ${ }^{12,13}$ Homogeneous Fenton at neutral $\mathrm{pH}$ could be carried out using substances able to solubilize iron over a wider range of $\mathrm{pH}$ than with conventional Fenton. These substances are named chelating agents 
and are able to form photoactive species $\left(\mathrm{Fe}^{3+}\right)$ that could be used to maintain the iron solubility. Chelation is useful for extending the $\mathrm{pH}$ range over which iron is soluble because the chelating ligand competes to advantage with hydroxide ion for coordination, and chelated complexes are typically soluble. ${ }^{\mathbf{1 4}}$ In general, chelating agents have several carboxylate groups linked to a number of tertiary nitrogen atoms. The functional groups form a stable and water-soluble complex with donor atoms such as metals. The metal cation is centered in the complex, and serves as the anchor site for coordinate bonds to either nitrogen or oxygen atoms. Unlike regular ligands, chelating agents can form multiple coordination bonds to a single metal ion. Hence, the Fenton oxidation system was modified by complexing the ferrous species with the ligands, such as saccharic acid, ${ }^{15}$ ethylene bis (oxyethylenenitrilo) tetra-acetic acid, ${ }^{\mathbf{1 6}}$ nitrilotriacetic acid, and citrate to increase the operating $\mathrm{pH}$ range of the classical Fenton system. ${ }^{17}$ Among these ligands, the ferric citrate complex is a good alternative for iron solubilization $^{18}$ because it is less toxic and readily available. More importantly, the ferric citrate complex can be used at $\mathrm{pH}$ values up to $9.0 .^{19}$ This suggests great potential for the application of lignocellulose pretreatment to enhance subsequent biological saccharification and biofuel fermentation, and to avoid subsequent wastewater treatment as well.

In this study, citric acid was used as iron chelate to enhance Fenton reagent pretreatment of rice straw. The conditions of Fenton oxidation with citric acid as iron chelate for enhancing rice straw pretreatment were first evaluated. Then, the composition and structural changes of lignocellulose were described. Last, the pretreated rice straw was saccharified by Ruminiclostridium thermocellum M3 to assess and verify the pretreatment efficiency. To the best of the author's knowledge, this research was the first assessment of citric acid as an iron chelate for lignocellulose pretreatment by the Fenton reaction.

\section{Method and materials}

\section{Preparation of raw feedstock}

Rice straw used in the experiments was obtained from Shuangyashan, Heilongjiang Province, China. The rice straw was washed and air dried, then ground using a high-speed rotary cutting mill (MF 10, IKA, Staufen, Germany) to yield powder with particle size $<1 \mathrm{~mm}$. Then, it was dried at $40{ }^{\circ} \mathrm{C}$ until constant weight was obtained. The prepared rice straw was then stored for future use.

\section{Fenton pre-treatment of rice straw}

Fenton pre-treatment of rice straw was carried out as described below: $\mathrm{FeCl}_{3}$ (Sigma Aldrich, St. Louis, MO) was diluted to $0.01 \mathrm{~mol} \mathrm{~L}^{-1}, 0.03 \mathrm{~mol} \mathrm{~L}^{-1}$, and $0.05 \mathrm{~mol} \mathrm{~L}^{-1}$. The prepared $\mathrm{FeCl}_{3}$ was then mixed with $\mathrm{H}_{2} \mathrm{O}_{2}(30 \% \mathrm{w} / \mathrm{w}$, Sigma Aldrich) with ratios ranging from $1: 10$ to $1: 100$ to carry out $\mathrm{Fe}^{3+} / \mathrm{H}_{2} \mathrm{O}_{2}$ pretreatment. $\mathrm{Fe}^{3+} / \mathrm{H}_{2} \mathrm{O}_{2} /$ citric acid pretreatment was processed with addition of citrate acid with the same concentration as $\mathrm{FeCl}_{3} \cdot{ }^{18,20,21}$ Milled rice straw (5 g) suspended in $\mathrm{FeCl}_{3}$ solution with solid loading of $10 \%(\mathrm{w} / \mathrm{v})$ in a $500 \mathrm{~mL}$ Erlenmeyer flask, was placed in a shaking incubator at $25{ }^{\circ} \mathrm{C}$ and $180 \mathrm{rpm}$ for a set duration. The $\mathrm{pH}$ of the solution ranged from 3.0 to 7.0, and was adjusted using $\mathrm{HCl}$ or $\mathrm{NaOH}$. After incubating for the desired pretreatment duration, the pretreated rice straw slurry was filtered through filtration cloth $(22-25 \mu \mathrm{m}$ pore size) to separate solid and liquid fractions. The filtered insoluble solids were washed with distilled water until the $\mathrm{pH}$ of the filtrate was neutral; then were subsequently dried in a vacuum-drying oven at $40{ }^{\circ} \mathrm{C}$ for $3 \mathrm{~d}$.

\section{Saccharification of pretreated and untreated rice straw}

To verify the pretreatment efficiency, rice straw was saccharified by $R$. thermocellum M3 isolated by Sheng et al. ${ }^{22}$ The saccharification process was carried out at $60{ }^{\circ} \mathrm{C}$ for $72 \mathrm{~h}$ using MA medium with $5 \mathrm{~g} \mathrm{~L}^{-1}$ pretreated/untreated rice straw as carbon source, as described by Sheng et al. ${ }^{23}$ Samples were taken every $6 \mathrm{~h}$ to determine oligosaccharide concentration, cell biomass, substrate degradation, and liquid-metabolites.

\section{Analytical methods}

Oligosaccharides, cell biomass, and liquid metabolites were determined according to the method described by Wang et al. ${ }^{24}$ The biogas composition was measured using a gas chromatograph (Agilent Technologies; model 6890N) equipped with a thermal conductivity detector using argon as the carrier gas (capable of detecting concentrations between 200 and 500 ppm). ${ }^{25}$ The cellulose degradation was determined in accordance with the method described by Huang et al. ${ }^{\mathbf{2 6}}$ The saccharification was calculated as a percent of the theoretical value. The $\mathrm{Fe}^{2+}$ concentration was determined using $o$-phenanthroline complexometry. ${ }^{27}$ The lignocellulose composition was determined using the automatic cellulose analyzer (ANKOM A200i, USA) in accordance with manufacturer instructions.

Cellulase and xylanase secreted by $R$. thermocellum M3 during rice straw saccharification were prepared according to the method described by Morag et al. ${ }^{28}$ Then, the cellulase and xylanase activities were determined by measuring the reducing sugars released from a certain substrate in accordance with the method described by Rattanachomsri et al. ${ }^{29}$ One unit of enzyme activity (IU) was defined as the amount of enzyme that produced $1 \mu \mathrm{mol}$ of reducing sugar per min. All assays were performed in triplicate, and the means were reported along with the standard deviations.

\section{Calculation of carbon balance}

Carbon mass balance was calculated as the output carbon mass divided by the input carbon mass: ${ }^{24}$ closure $(\%)=\left(\left[\sum C_{\text {out }}\right] /\right.$ $\left.\left[\sum C_{\mathrm{in}}\right]\right) \times 100$, where $\sum C_{\text {out }}$ is total carbon recovery in grams and $\sum C_{\text {in }}$ is initial carbon in grams. Evaluation of the carbon mass balance of cellulosic substrates requires information on initial and final carbon contributions, including cellulose concentrations, cell mass concentrations, soluble protein concentrations, oligosaccharide concentrations, total $\mathrm{CO}_{2}$, and organic acids. All the parameters were measured immediately when inoculation was near completion and every $6 \mathrm{~h}$ thereafter 
until the end of cultivation $(72 \mathrm{~h})$. The carbon contribution from the medium components (primarily yeast extract) was measured with a CHN analyzer (CHNS/O elemental analyzer 2400; Perkin-Elmer, Norwalk, CT). The carbon content of the soluble proteins was estimated to be $50 \%$ (wt/wt) of the total protein mass. The concentration of $\mathrm{CO}_{2}$ was measured as described by Wang et al. ${ }^{24}$

\section{Structural features of the pre-treated rice straw}

The microstructural changes in the rice straw after pretreatment were detected by scanning electron microscopy (SEM). Specimens mounted on stubs coated with gold using a sputter coater were observed using SEM (JEOL JSM-840). To characterize the changes in the functional groups of the pretreated rice straw, Fourier transform infrared spectroscopy (FTIR) was carried out using a Magna-IR 750 (Nicolet Instrument Co., USA) as described by Zhao et al. $^{2}$ Spectra were recorded between 4000 and $400 \mathrm{~cm}^{-1}$. The background spectrum of pure potassium bromide was subtracted from the sample spectrum. X-ray diffraction (XRD) measurements were performed on a Philips PW3040/00 X'Pert MPD system. The diffracted intensity of $\mathrm{Cu}$ $\mathrm{K} \alpha$ radiation $(\lambda=0.1542 \mathrm{~nm} ; 50 \mathrm{kV}$ and $40 \mathrm{~mA})$ was measured in a $2 \theta$ range between $10^{\circ}$ and $50^{\circ} .^{30}$ The crystallinity index (ICR) of the materials was computed from XRD patterns. It was calculated according to: ${ }^{31}$

$$
\mathrm{ICR}=1-I_{\min } / I_{\max }
$$

where ICR is the crystallinity index, $I_{\min }$, intensity at the minimum of the crystalline peak $\left(18^{\circ}<2 \theta<19^{\circ}\right)$ and $I_{\max }$, intensity at its maximum $\left(22^{\circ}<2 \theta<23^{\circ}\right)$.

\section{Results and discussion}

\section{Effect of pH on Fenton pretreatment of rice straw}

To test the effect of citric acid addition on the Fenton reaction under variable $\mathrm{pH}$, rice straw was pretreated using $\mathrm{Fe}^{3+} / \mathrm{H}_{2} \mathrm{O}_{2} /$ citric acid and $\mathrm{Fe}^{3+} / \mathrm{H}_{2} \mathrm{O}_{2}$ at varied $\mathrm{pH}$. With an initial $\mathrm{Fe}^{3+}$ concentration of $0.03 \mathrm{~mol} \mathrm{~L}^{-1}$ and $\mathrm{Fe}^{3+} / \mathrm{H}_{2} \mathrm{O}_{2}$ ratio of $1 / 100$ at $25^{\circ} \mathrm{C}$, the Fenton reaction was performed in a range of $\mathrm{pH}$ from 3 to 7 for $24 \mathrm{~h}$. The change in composition of the rice straw after $\mathrm{Fe}^{3+} / \mathrm{H}_{2} \mathrm{O}_{2}$ and $\mathrm{Fe}^{3+} / \mathrm{H}_{2} \mathrm{O}_{2} /$ citric acid pretreatment were determined and the results are shown in Fig. $1 \mathrm{a}$ and $\mathrm{b}$. When the rice straw was pretreated by $\mathrm{Fe}^{3+} / \mathrm{H}_{2} \mathrm{O}_{2}$, the lignin degradation gradually declined as the $\mathrm{pH}$ rose from 3 to 7 . Similarly, the cellulose and hemicellulose degradation both declined as the $\mathrm{pH}$ rose (Fig. 1a). At $\mathrm{pH} \mathrm{3}$, the degradation ratio of lignin, cellulose, and hemicellulose was $60.4 \%$ to $31.2 \%$ to $33.5 \%$. As $\mathrm{pH}$ rose to ' 6 ', the values declined to $18.9 \%$ (lignin), $18.3 \%$ (cellulose), and $26.4 \%$ (hemicellulose). When the pH rose to ' 7 ', the lignin degradation ratio further decreased to $12.1 \%$, and the hemicellulose and cellulose degradation declined to $20.8 \%$ and $8.2 \%$, respectively. However, when citric acid was added to the Fenton reagent, the lignin degradation ratios were all greater than $50 \%$ at pH 3-6 (Fig. 1b). Meanwhile, the cellulose and hemicellulose degradation declined from $35.3 \%$ and $34.8 \%(\mathrm{pH}$ 3) to $10.2 \%$ and $21.4 \%(\mathrm{pH} 6)$. Lignin can impede enzymatic hydrolysis by blocking access to cellulase as well as by unproductive binding with the cellulose and hemicellulose. ${ }^{32,33}$ Therefore, the removal of lignin could increase the pore size and accessible surface of rice straw and enhance the cellulolytic enzyme access to cellulose and hemicellulose, resulting in increased sugar yield. ${ }^{33,34}$ Thus, an ideal pretreatment method would be to remove lignin to get the maximum holocellulose access. It has been reported that the $\mathrm{OH}$ radical yielded in the Fenton action is a powerful oxidant that can depolymerize polysaccharides via hydrogen abstraction, and can also attack lignin through demethylation/demethoxylation. ${ }^{35,36}$ Fenton reagent with citric acid was able to increase the solubility of iron and enabled the Fenton system to operate at a relatively wider $\mathrm{pH}$, as described by De and Huang. ${ }^{37,38}$ In this research, it was found that the $\mathrm{Fe}^{3+} / \mathrm{H}_{2} \mathrm{O}_{2} /$ citric acid pretreatment could degrade holocellulose in a selective manner while degrading lignin in a non-selective way under different $\mathrm{pH}$ condition; that is, the Fenton reagent used in this study preferentially degraded cellulose and hemicellulose in an acidic environment, but did not do so with lignin. These results illustrated that the addition of citric acid to Fenton reagent was effective for removing lignin as well as for preserving holocellulose at near neutral $\mathrm{pH}$.

Actually, the pretreatment behavior described above is just like some biological degradation process in nature. Some species of white rot fungi, such as Ceriporiopsis subvermispora, are able to decompose lignin in woody cell walls without excessive damage to the cellulose ${ }^{39}$ It has been reported that selective white rot fungi secrete low-molecular-mass chelators that inhibit the depolymerization of cellulose by inhibiting the redox cycling of iron ions in the Fenton system during freeradical-mediated lignin biodegradation. Moreover, it was demonstrated that some alkylitaconic acids, such as ceriporic acid, inhibited de-polymerization of cellulose by the Fenton reaction even in the presence of $\mathrm{Fe}^{3+}$-reductants such as hydroquinone. ${ }^{40}$ As the same phenomenon was found in this research, a preliminary conclusion can be given that the citric acid could be able to reduce the cost of processing holocellulose during the Fenton action.

As reported by Subramanian, the amount of $\mathrm{Fe}^{2+}$ generated is crucial to drive the Fenton reaction efficiently, and the chelating agent promoted $\mathrm{Fe}^{2+}$ dissolution..$^{15}$ Therefore, to understand the enhancement mechanism of citric acid on the performance of Fenton pretreatment, the generation of $\mathrm{Fe}^{2+}$ by $\mathrm{Fe}^{3+} / \mathrm{H}_{2} \mathrm{O}_{2} /$ citric acid and $\mathrm{Fe}^{3+} / \mathrm{H}_{2} \mathrm{O}_{2}$ was tested at different $\mathrm{pH}$ as well (Fig. 1c and d). The amount of $\mathrm{Fe}^{2+}$ generated by $\mathrm{Fe}^{3+} / \mathrm{H}_{2} \mathrm{O}_{2} /$ citric acid at $\mathrm{pH}$ 3-6 was around $7.6 \mu \mathrm{mol} \mathrm{L}^{-1}$, when the $\mathrm{pH}$ was raised to '7', the $\mathrm{Fe}^{2+}$ concentration decreased to $2.4 \mu \mathrm{mol} \mathrm{L}^{-1}$. This was consistent with the change in chemical composition of the lignocellulose as mentioned above. However, the $\mathrm{Fe}^{2+}$ generated by $\mathrm{Fe}^{3+} / \mathrm{H}_{2} \mathrm{O}_{2}$ exhibited a different model. The maximum $\mathrm{Fe}^{2+}$ concentration was obtained at pH $3\left(7.8 \mu \mathrm{mol} \mathrm{L}^{-1}\right)$ which was similar with the result from $\mathrm{Fe}^{3+} / \mathrm{H}_{2} \mathrm{O}_{2} /$ citric acid, but when the $\mathrm{pH}$ was raised to 6 , the $\mathrm{Fe}^{2+}$ concentration was just $40 \%$ of that from $\mathrm{Fe}^{3+} / \mathrm{H}_{2} \mathrm{O}_{2} /$ citric. These results confirmed the citric acid was able to increase the $\mathrm{Fe}^{2+}$ concentration during the Fenton reaction even at $\mathrm{pH} 6$. 

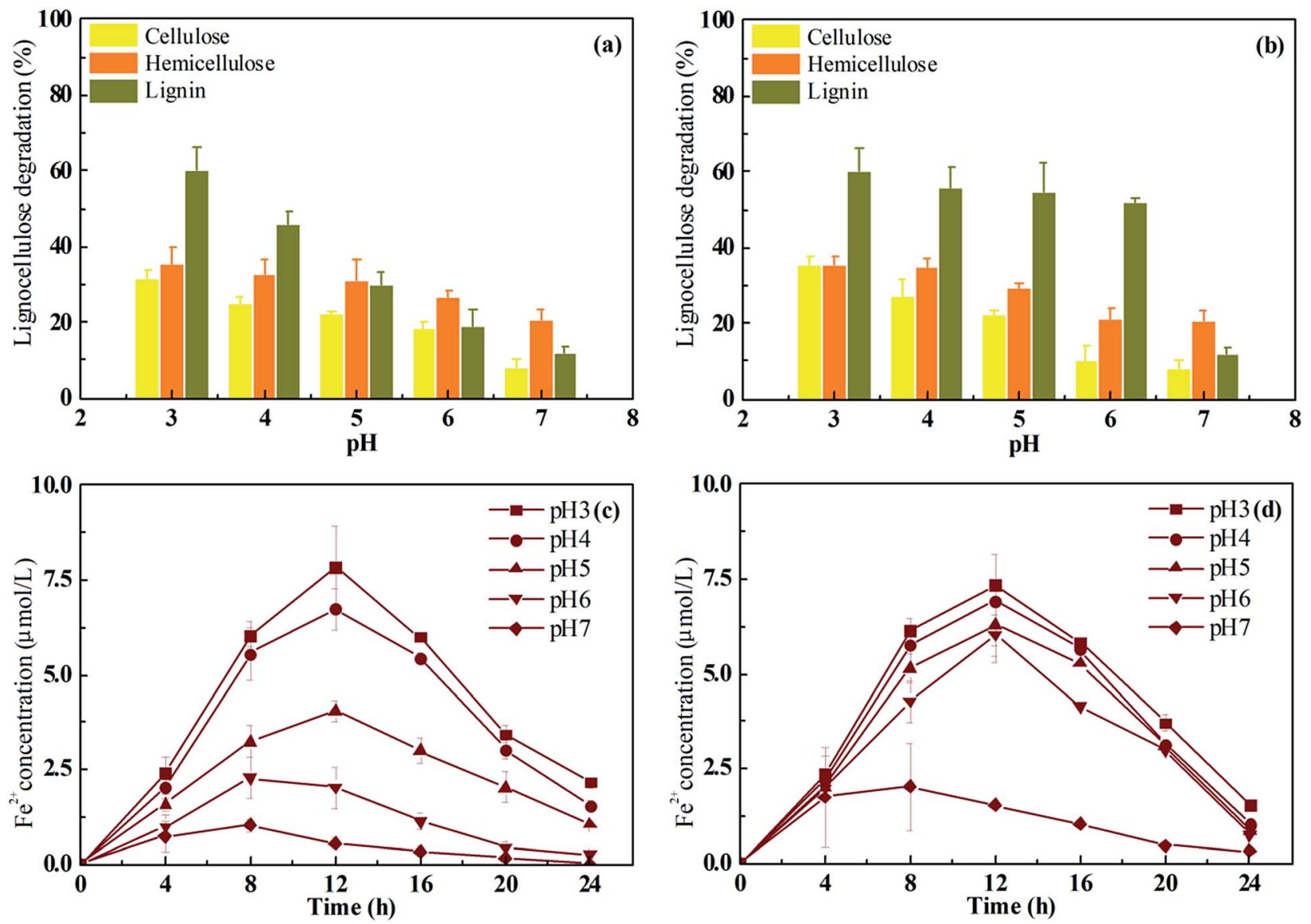

Fig. 1 Lignocellulose degradation of pre-treated straw and $\mathrm{Fe}^{2+}$ yield during Fenton action under different $\mathrm{pH}$. (a) Composition of rice straw pretreated by Fe ${ }^{3+} / \mathrm{H}_{2} \mathrm{O}_{2}$. (b) Composition of rice straw pre-treated by Fe $\mathrm{Fe}^{3+} / \mathrm{H}_{2} \mathrm{O}_{2} /$ citric acid. (c) Moles of Fe $\mathrm{Ce}^{2+}$ generated by Fe $\mathrm{Cu}^{3+}$ without citric acid at different $\mathrm{pH}$. (d) Moles of $\mathrm{Fe}^{2+}$ generated by $\mathrm{Fe}^{3+}$ in presence of citric acid at different $\mathrm{pH}$.

Pretreated rice straw was saccharified by $R$. thermocellum $\mathrm{M} 3$ to compare and evaluate the pretreatment efficiency of the Fenton reagent used in this research. The saccharification profile was consistent with the $\mathrm{Fe}^{2+}$ yield during the Fenton reaction (Fig. 2). When the rice straw was pretreated with $\mathrm{Fe}^{3+} / \mathrm{H}_{2} \mathrm{O}_{2}$, the saccharification ratio declined gradually from

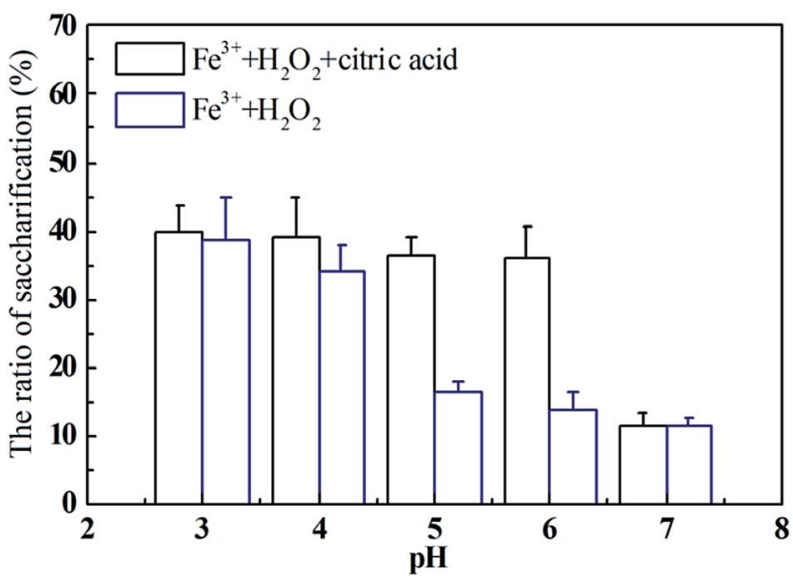

Fig. 2 Saccharification ratio of rice straw pre-treated by Fenton with/ without citric acid under different $\mathrm{pH}$.
$38.8 \%$ at $\mathrm{pH} 3-13.8 \%$ at $\mathrm{pH}$ 6. In contrast, the saccharification ratio of rice straw pretreated by $\mathrm{Fe}^{3+} / \mathrm{H}_{2} \mathrm{O}_{2} /$ citric acid was constant at around $38 \%$ at $\mathrm{pH} 3-6$; no significant difference $(P>$ 0.05 ) was found. The increase in the saccharification ratio of rice straw pretreated with $\mathrm{Fe}^{3+} / \mathrm{H}_{2} \mathrm{O}_{2} /$ citric acid at relatively higher $\mathrm{pH}$ should be attributed to the higher amount of $\mathrm{Fe}^{2+}$ released. ${ }^{41}$ In previous studies, Jun and Kim used $0.05 \mathrm{~mol} \mathrm{~L}^{-1}$ $\mathrm{Fe}^{3+}$ and $2.25 \mathrm{~mol} \mathrm{~L}^{-1} \mathrm{H}_{2} \mathrm{O}_{2}$ to pretreat rice straw at $\mathrm{pH} 3$ and then hydrolyze the pretreated feedstock with cellulase (60 FPU), after which a saccharification ratio of $38.6 \%$ was obtained. ${ }^{8} \mathrm{Li}$ et al. employed Fenton regent $\left(1 \mathrm{~g} \mathrm{~L}^{-1} \mathrm{FeSO}_{4} \cdot 7 \mathrm{H}_{2} \mathrm{O}\right.$ and $30 \mathrm{~g} \mathrm{~L}^{-1}$ $\mathrm{H}_{2} \mathrm{O}_{2}$ ) for corn straw pretreatment at $20^{\circ} \mathrm{C}$. After hydrolysis by cellulase ( $3 \mathrm{FPU}$ per $\mathrm{g}$ ), the saccharification ratio could reach $26.7 \%{ }^{42}$ However, these Fenton reactions were all performed at $\mathrm{pH} \sim 3-4$ to guarantee the quantity of lignin removal. Compared with previous studies, the results obtained in this research suggest a feasible way to extend the $\mathrm{pH}$ of the Fenton reaction to enhance lignocellulose pretreatment.

\section{Effect of $\mathrm{FeCl}_{3}$ and $\mathrm{H}_{2} \mathrm{O}_{2}$ concentrations on Fenton pretreatment of rice straw}

The concentrations and ratio of $\mathrm{Fe}^{3+} / \mathrm{H}_{2} \mathrm{O}_{2}$ were the key parameters in the Fenton reaction. ${ }^{43}$ After the pretreatment 
efficiency of $\mathrm{Fe}^{3+} / \mathrm{H}_{2} \mathrm{O}_{2}$ /citric at $\mathrm{pH} 6$ was verified in this study, the concentration ratio of $\mathrm{FeCl}_{3}$ and $\mathrm{H}_{2} \mathrm{O}_{2}$ used in the pretreatment was tested to maximize the saccharification ratio of rice straw by $R$. thermocellum M3. The concentrations of $\mathrm{FeCl}_{3}$ and $\mathrm{H}_{2} \mathrm{O}_{2}$ were varied in the range $0.01-0.05 \mathrm{~mol} \mathrm{~L}^{-1}$ and $0.25-$ $5.0 \mathrm{~mol} \mathrm{~L}^{-1}$, respectively, to yield different ratios of $\mathrm{Fe}^{3+}$ to $\mathrm{H}_{2} \mathrm{O}_{2}$ (i.e., $1: 25,1: 50,1: 75$, and $1: 100$ ), the concentrations of citric acid and $\mathrm{FeCl}_{3}$ were the same. All the reaction conditions were fixed at $\mathrm{pH} 6,25^{\circ} \mathrm{C}, 180 \mathrm{rpm}$, and solid loading of $10 \%$, for $24 \mathrm{~h}$. As shown in Fig. 3, for a given concentration of $\mathrm{Fe}^{3+}$, the digestibility of pretreated rice straw was enhanced by increase in the concentration of $\mathrm{H}_{2} \mathrm{O}_{2}$, due to the higher oxidizing ability of $\mathrm{H}_{2} \mathrm{O}_{2}$. It was interesting to note that when the concentration of $\mathrm{H}_{2} \mathrm{O}_{2}$ was fixed, the saccharification performance peaked at the $\mathrm{Fe}^{3+}$ concentration of $0.03 \mathrm{~mol} \mathrm{~L}^{-1}$ rather than at $0.05 \mathrm{~mol}$
$\mathrm{L}^{-1}$. A similar trend was obtained for the composition of pretreated rice straw: more lignin was degraded with $0.03 \mathrm{~mol} \mathrm{~L}^{-1}$ $\mathrm{Fe}^{3+}$ than with $\mathrm{Fe}^{3+} 0.05$ mol L ${ }^{-1}$. Theoretically, the oxidation of the Fenton reagent was positively correlated with $\mathrm{Fe}^{3+} / \mathrm{Fe}^{2+}$ and the $\mathrm{H}_{2} \mathrm{O}_{2}$ concentration; however, in this study, an obvious decrease in the oxidation was obtained when the $\mathrm{Fe}^{3+}$ was increased from 0.03 to $0.05 \mathrm{~mol} \mathrm{~L}^{-1}$. It has been reported that the presence of chloride in the reaction medium could affect the Fenton process by forming $\mathrm{Fe}^{2+} / \mathrm{Fe}^{3+}$-inorganic anion complexes. In addition, inorganic anions could also scavenge reactive oxygen species generated during the Fenton process. ${ }^{15}$ Chloride ions act by scavenging the hydroxyl radicals generated in the Fenton reaction. ${ }^{44}$ Therefore, the decline of oxidation with $0.05 \mathrm{~mol} \mathrm{~L}^{-1} \mathrm{Fe}^{3+}$ is attributed to the higher chloride ion concentration.
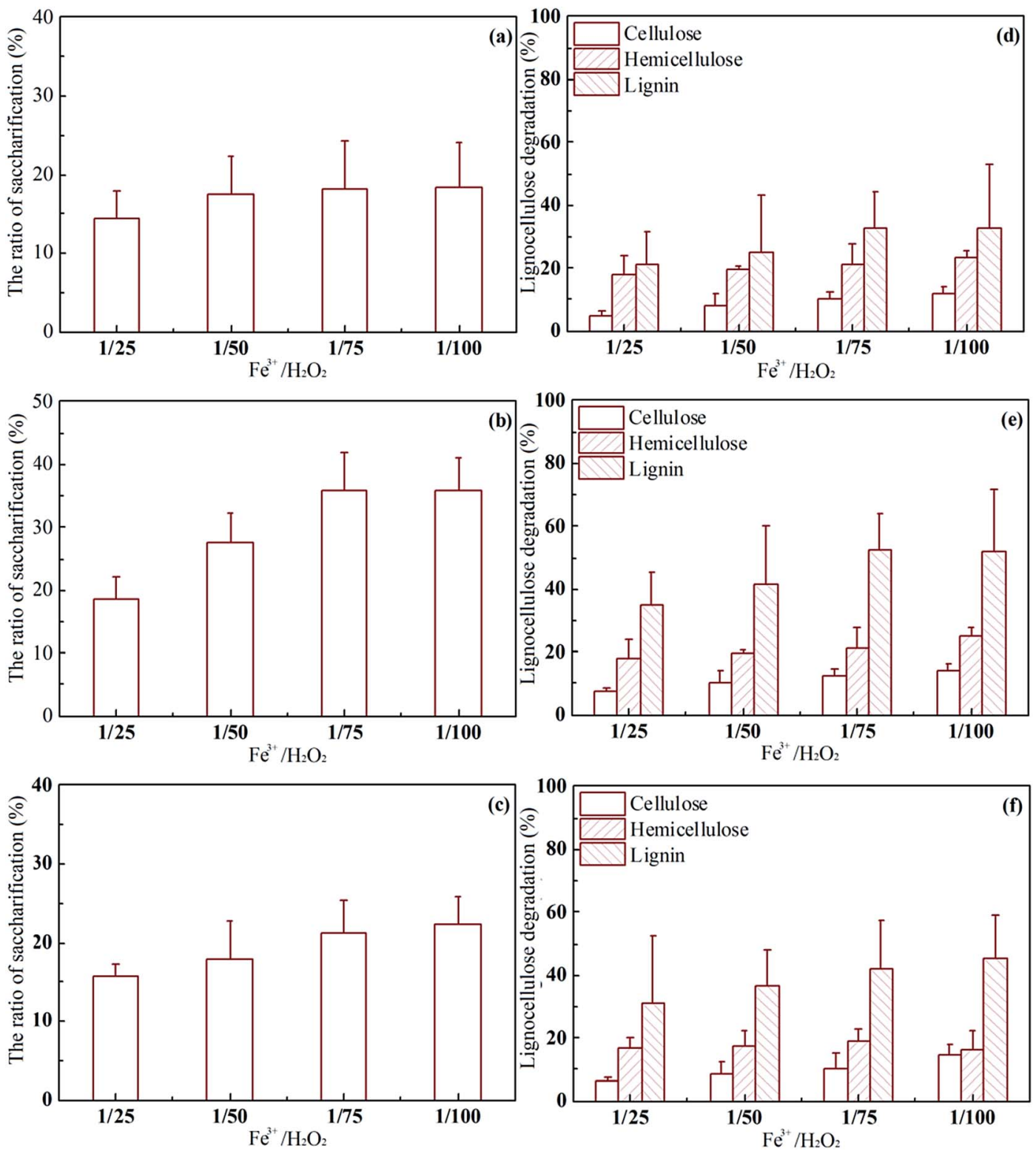

Fig. 3 Effect of $\mathrm{FeCl}_{3}$ and $\mathrm{H}_{2} \mathrm{O}_{2}$ concentrations on the saccharification ratio and the composition of rice straw pre-treated by $\mathrm{Fe}^{3+} / \mathrm{H}_{2} \mathrm{O}_{2} / \mathrm{citric}$ acid under $\mathrm{pH}$ 6: (a) and (d) initial $\mathrm{Fe}^{3+} 0.01 \mathrm{~mol} \mathrm{~L}^{-1}$, (b) and (e) initial Fe $\mathrm{F}^{3+} 0.03 \mathrm{~mol} \mathrm{~L}^{-1}$, (c) and (f) initial Fe $0.05 \mathrm{~mol} \mathrm{~L}^{-1}$. 
When citric acid was removed from the Fenton reagent, as in Fig. $\mathrm{S} 1, \uparrow$ the saccharification ratios for all pretreated rice straw were about $13 \%$ : similar to untreated rice straw. The lignocellulose degradation was consistent with the saccharification profile, and all the pretreated samples maintained a similar value. The cellulose, hemicellulose, and lignin content was about 20, 25, and $20 \%$, respectively. The results suggested that without citric acid, the $\mathrm{Fe}^{3+}$ and $\mathrm{H}_{2} \mathrm{O}_{2}$ concentration have little effect on pretreatment performance at $\mathrm{pH}<6$.

Above all, although $36.8 \%$ of the theoretical maximum oligosaccharide yield was obtained at the initial $\mathrm{Fe}^{3+}$ concentration of $0.03 \mathrm{~mol} \mathrm{~L} \mathrm{~L}^{-1}$ and $\mathrm{Fe}^{3+} / \mathrm{H}_{2} \mathrm{O}_{2}$ ratio of $1 / 100$, the difference from the result obtained at initial $\mathrm{Fe}^{3+} 0.03 \mathrm{~mol} \mathrm{~L}^{-1}$ and $\mathrm{Fe}^{3+} / \mathrm{H}_{2} \mathrm{O}_{2} 1 / 75(35.7 \%)$ was not significant $(P>0.05)$. Therefore, considering both the cost of input and saccharification efficiency, the combination of $\mathrm{Fe}^{3+} 0.03 \mathrm{~mol} \mathrm{~L}^{-1}$, citric acid $0.03 \mathrm{~mol} \mathrm{~L}^{-1}$ and $\mathrm{Fe}^{3+} / \mathrm{H}_{2} \mathrm{O}_{2} 1 / 75$ was selected to carry out the following experiments.

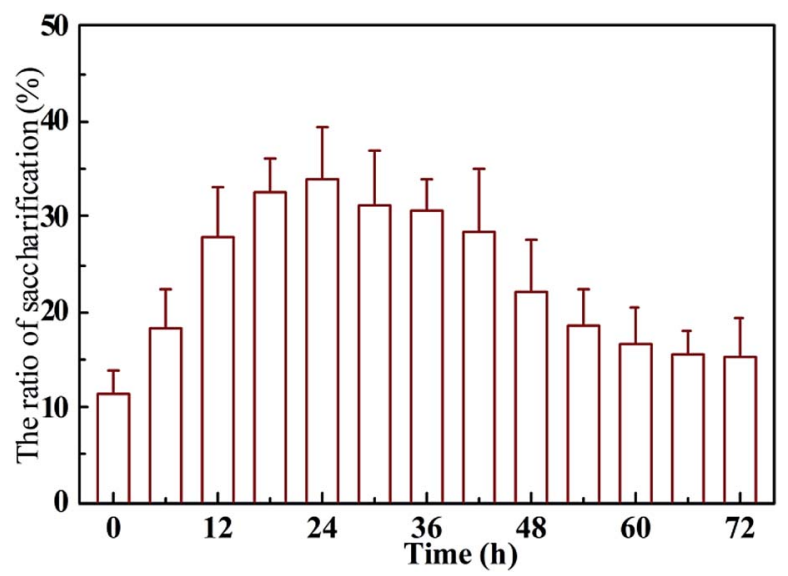

Fig. 4 Effect of the duration of the Fenton reaction on the saccharification of rice straw pre-treated with $\mathrm{Fe}^{3+} / \mathrm{H}_{2} \mathrm{O}_{2} /$ citric acid at $\mathrm{pH} 6$.

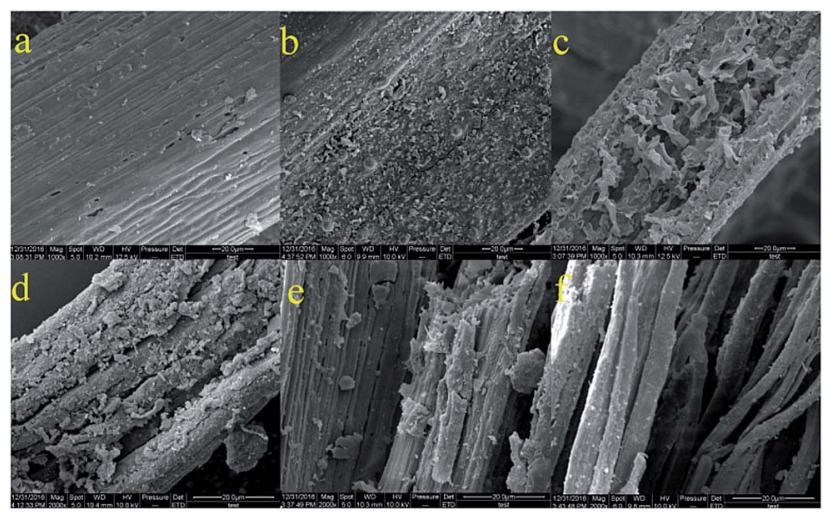

Fig. 5 Scanning electron micrographs (SEMs) of pre-treated/ untreated rice straw at $\mathrm{pH}$ 6: (a) surface of untreated rice straw. (b) Surface of rice straw pre-treated with $\mathrm{Fe}^{3+} / \mathrm{H}_{2} \mathrm{O}_{2}$. (c) Surface of rice straw pre-treated with $\mathrm{Fe}^{3+} / \mathrm{H}_{2} \mathrm{O}_{2} /$ citric acid. (d) Vascular bundle of untreated rice straw. (e) Vascular bundle of rice straw pre-treated with $\mathrm{Fe}^{3+} / \mathrm{H}_{2} \mathrm{O}_{2}$. (f) Vascular bundle of rice straw pre-treated with $\mathrm{Fe}^{3+} /$ $\mathrm{H}_{2} \mathrm{O}_{2}$ /citric acid.

\section{Effect of reaction duration on Fenton pretreatment of rice} straw

The pre-treatment time is another key factor in Fenton pretreatment performance. Therefore, it was necessary to evaluate the effects of Fenton pretreatment duration on rice straw. Rice straw was pretreated with the established Fenton protocol mentioned above (solid loading 10\%, $0.03 \mathrm{~mol} \mathrm{~L} \mathrm{~L}^{-1} \mathrm{Fe}^{3+}$, $0.03 \mathrm{~mol} \mathrm{~L}^{-1}$ citric acid, $\mathrm{Fe}^{3+} / \mathrm{H}_{2} \mathrm{O}_{2} 1 / 75, \mathrm{pH}$ 6) for $72 \mathrm{~h}$. Samples were taken every $6 \mathrm{~h}$ to evaluate the saccharification efficiency and lignocellulose composition. The results are shown in Fig. 4. After the Fenton reagent was added to the raw feedstock saccharification gradually increased and peaked at $35.7 \%$ with pretreatment for $24 \mathrm{~h}$. After $24 \mathrm{~h}$, the rice straw saccharification declined gradually, which was probably because the excessive pretreatment time led to oxidation of more of the carbohydrates embedded in the lignocellulose. To give further insight into this phenomenon, the carbon balance of the Fenton-reagent pretreated rice straw was evaluated based on the holocellulose consumed, the production of cell biomass (total protein), oligosaccharides, and metabolic end products. As shown in Table $\mathrm{S} 1, \dagger$ when the pretreatment time was extended beyond $24 \mathrm{~h}$, more carbon flowed into the oligosaccharides during saccharification by $R$. thermocellum M3. Specifically, when saccharification was carried out after pretreatment time $>24 \mathrm{~h}$, $36.4 \%$ carbon flowed into by-products such as formic acid and
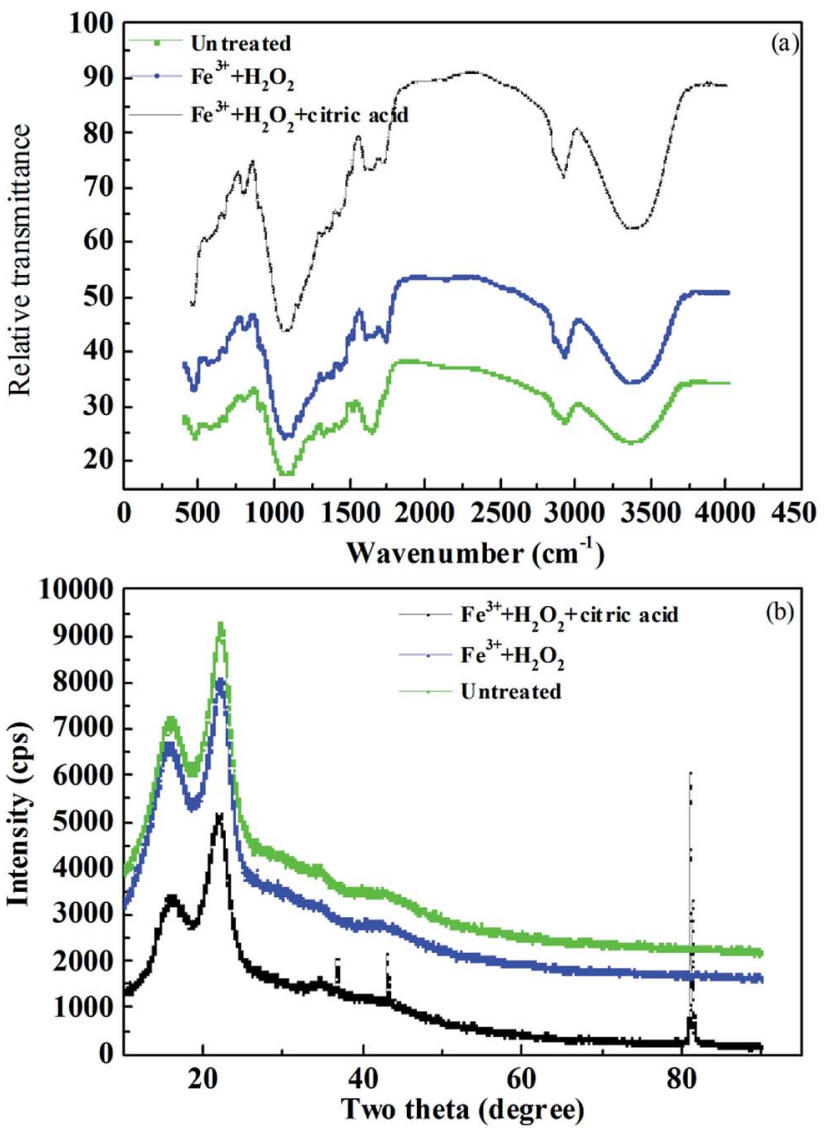

Fig. 6 FTIR spectra of pre-treated/untreated rice straw (a), and XRD patterns of pre-treated/untreated rice straw (b). 
carbon dioxide. ${ }^{45}$ With further increase in the fermentation time to $48 \mathrm{~h}$, the loss of total carbon was $54.4 \%$, but the carbon flow into oligosaccharide dropped to $19.6 \%$. The carbon flow into the oligosaccharide reached the lowest level (15.7\%) when the pretreatment time was $72 \mathrm{~h}$. It is obvious that the weight of oligosaccharide had a negative correlation with the amount of metabolites. The weight of oligosaccharide peaked at pretreatment time of $24 \mathrm{~h}$, but the metabolites (lactate, acetate, ethanol, and carbon dioxide) weight was just $6.8 \%$ at this point. Meanwhile, the maximum weight of metabolites $(17.6 \%)$ was obtained in untreated rice straw, while oligosaccharide was just $14.7 \%$. This phenomenon indicated that the Fenton pretreatment was of great benefit to the saccharification of the lignocellulosic feedstock and drove the carbon flow into carbohydrates rather than into the volatile acids and carbon dioxide.

In contrast to the profile of the oligosaccharide yield, the cell mass concentration in relation to different pre-treatment time did not show significant differences $(P>0.05)$. The bacteria decompose cellulose/hemicellulose by synthesis of cellulosomes, which are located at the cell surface. Therefore, the cell mass weight can be considered an index of the quantity of cellulase. The results suggested that the rice straw pre-treated by Fenton reagent did not affect the cellulase synthesis by the cellulosic bacteria. In general, Fenton pre-treatment with citric
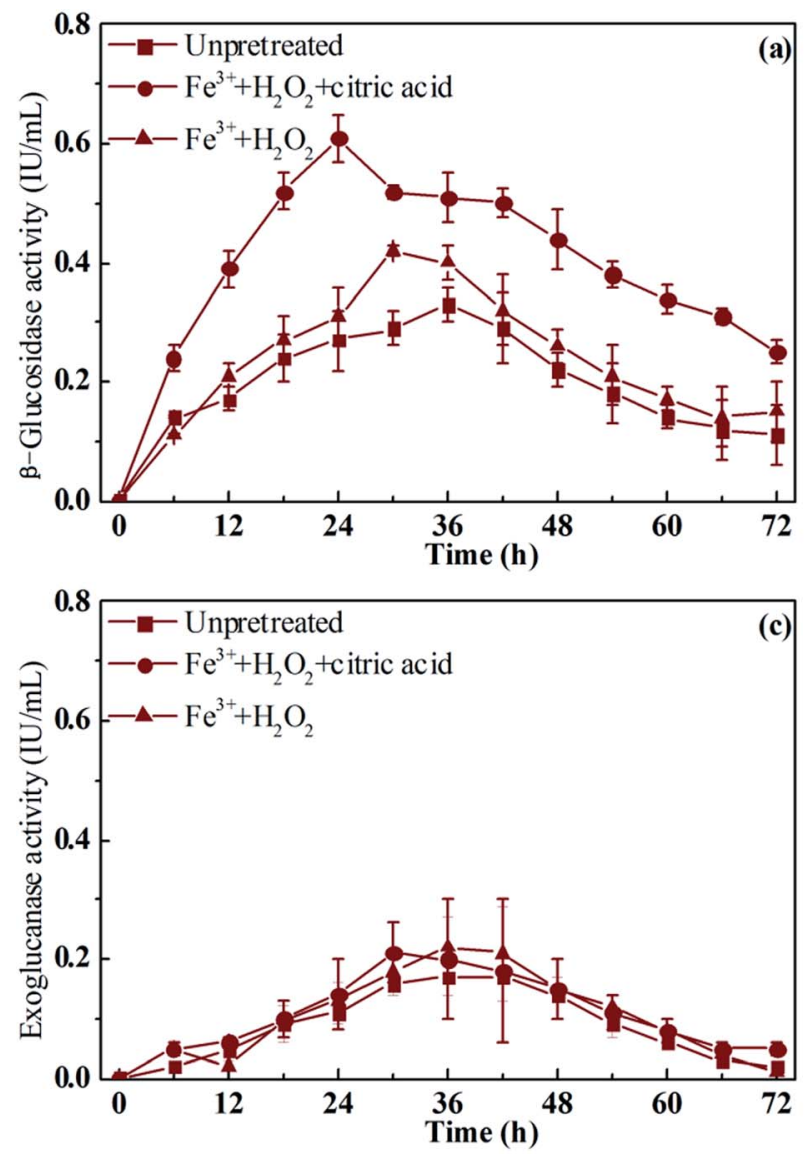

addition was a feasible method for the saccharification of lignocellulosic feedstock.

When the citric acid was removed from the Fenton solution, the saccharification ratio seemed unchanged during the first $48 \mathrm{~h}$ (Fig. S2 $\dagger$ ) (i.e., the value was similar to that of untreated rice straw). However, $48 \mathrm{~h}$ later, the saccharification ratio gradually declined, when the rice straw was pretreated with $\mathrm{Fe}^{3+}$ and $\mathrm{H}_{2} \mathrm{O}_{2}$ for $72 \mathrm{~h}$, the saccharification ratio was just about 5\%, even lower than the untreated sample. Citric acid enables the Fenton system to be operated at a relatively wider $\mathrm{pH}$; without citric acid, the pre-treatment does not work at pH 6, and extending the pre-treatment time is useless. Therefore, pretreatment for $24 \mathrm{~h}$ using the $\mathrm{Fe}^{3+} / \mathrm{H}_{2} \mathrm{O}_{2} /$ citric acid combination is optimal for achieving a relatively high saccharification ratio at room temperature.

\section{Structural features of Fenton-pretreated rice straw}

The different morphological changes induced by $\mathrm{Fe}^{3+} / \mathrm{H}_{2} \mathrm{O}_{2} /$ citric acid and $\mathrm{Fe}^{3+} / \mathrm{H}_{2} \mathrm{O}_{2}$ pretreatments under optimal conditions were examined using SEM to provide insight into modifications of the rice straw structure. Fig. 5a and $\mathrm{d}$ show the compact and rigid structure of untreated rice straw. After $\mathrm{Fe}^{3+} /$ $\mathrm{H}_{2} \mathrm{O}_{2}$ /citric acid pretreatment, many erosion troughs and many holes and cracks were exhibited in the surface of the pretreated rice straw. The structure became loose, and the surface of the
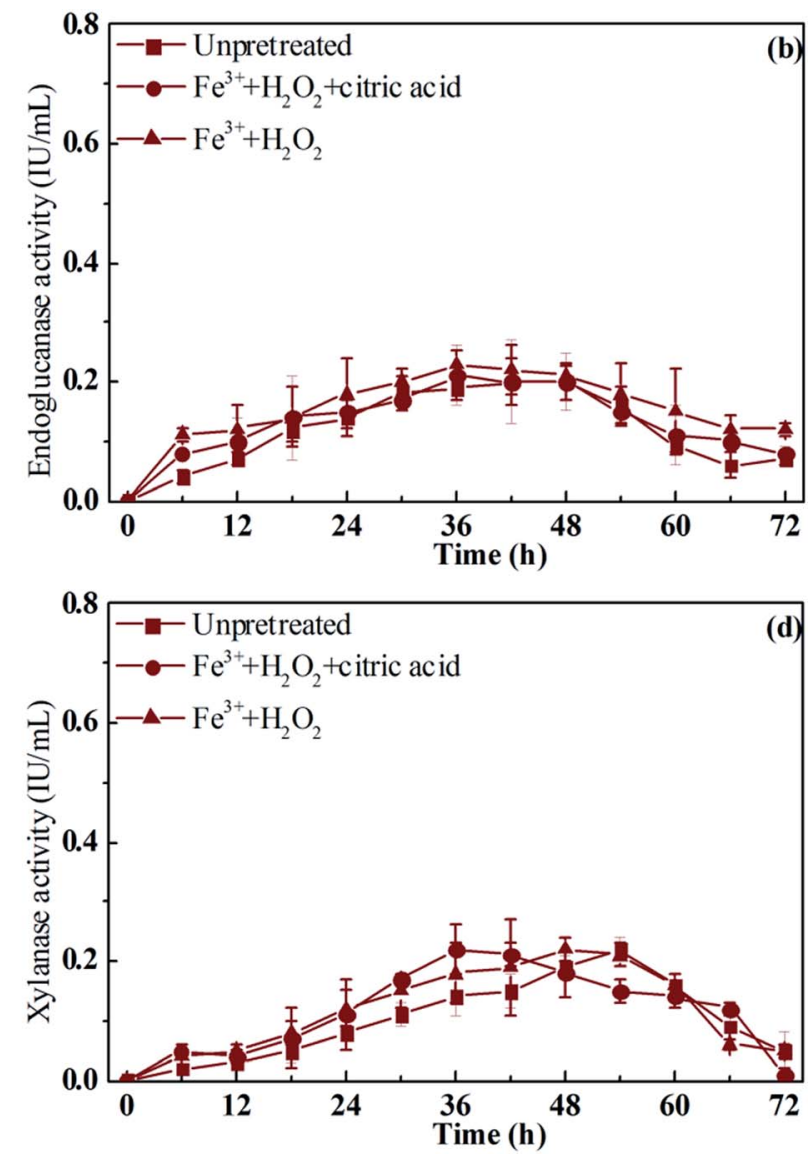

Fig. 7 Cellulase and xylanase activities of pre-treated/untreated rice straw during saccharification. 
substrate seemed to be substantially disrupted with a greater area of the surface showing fragmentation (Fig. 5c and f). When the rice straw was pretreated with $\mathrm{Fe}^{3+} / \mathrm{H}_{2} \mathrm{O}_{2}$, the structure of rice straw was similar to the untreated sample (Fig. $5 \mathrm{~b}$ and e), with barely any erosion or holes on the surface. Moreover, the vascular bundle of pre-treated rice straw was close-knit, suggesting that the $\mathrm{Fe}^{3+} / \mathrm{H}_{2} \mathrm{O}_{2}$ did not effectively disrupt the structure of the rice straw at $\mathrm{pH} 6$. This condition confirmed the improved lignin degradation and better preservation of holocellulose with $\mathrm{Fe}^{3+} / \mathrm{H}_{2} \mathrm{O}_{2} /$ citric acid pre-treatment, compared to the counterpart without citric acid, at pH 6.

Fourier transform infrared spectroscopy (FTIR) was applied as an analytical tool to further determine the chemical changes in rice straw after $\mathrm{Fe}^{3+} / \mathrm{H}_{2} \mathrm{O}_{2} /$ citric acid and $\mathrm{Fe}^{3+} / \mathrm{H}_{2} \mathrm{O}_{2}$ pretreatments. As presented in Fig. 6a, the functional group changes in pre-treated rice straw were particularly reflected in the fingerprint region of the absorbance spectra. The band at approximately $1512 \mathrm{~cm}^{-1}$ corresponded to aromatic skeletal vibration $\mathrm{C}=\mathrm{C}$ of lignin. ${ }^{\mathbf{4 6}}$ The intensity of the peak at this wavelength was lower than for untreated rice straw, and for that pretreated with $\mathrm{Fe}^{3+} / \mathrm{H}_{2} \mathrm{O}_{2}$, indicating that the content of lignin in rice straw decreased after $\mathrm{Fe}^{3+} / \mathrm{H}_{2} \mathrm{O}_{2} /$ citric acid treatment. The crystalline index is considered a crucial factor that could influence the enzymatic saccharification of lignocellulosic biomass. ${ }^{47}$ In order to investigate the cellulose crystallinity and changes promoted by $\mathrm{Fe}^{3+} / \mathrm{H}_{2} \mathrm{O}_{2} /$ citric acid pretreatment, X-ray diffraction analysis was performed. X-ray diffraction pattern of pre-treated and untreated rice straw are displayed in Fig. 6b. The XRD patterns shows that the ordered structure of the crystalline index on the untreated rice straw is not disrupted. The crystalline index of untreated rice straw was 0.41 . After pretreatment with $\mathrm{Fe}^{3+} / \mathrm{H}_{2} \mathrm{O}_{2} /$ citric acid for $24 \mathrm{~h}$, the crystalline index of the rice straw declined to 0.21 , which much less than the untreated rice straw or that pre-treated with $\mathrm{Fe}^{3+} / \mathrm{H}_{2} \mathrm{O}_{2}$ (0.35). When Yang et al. pretreated corn stover with alkali and biological pre-treatments, the crystalline index was reduced by $6.84 \% .^{48} \mathrm{Xu}$ et al. pre-treated corn stover with alkali, and the crystalline index increased from 0.43 to $0.51 .^{49}$ These results indicate that the effects of $\mathrm{Fe}^{3+} / \mathrm{H}_{2} \mathrm{O}_{2}$ /citric acid pretreatment for both lignin removal and decreasing the crystalline zones of cellulose were comparable or even greater than that of the thermochemical pre-treatments used in other research (Fig. 6).

\section{Effect of Fenton pretreatment on cellulase and xylanase activity}

The activity of the cellulase and xylanase secreted by $R$. thermocellum M3 during the entire saccharification process is shown in Fig. 7a-d. When the rice straw was pretreated with $\mathrm{Fe}^{3+} / \mathrm{H}_{2} \mathrm{O}_{2} /$ citric acid, the $\beta$-glucosidase activity increased rapidly during the initial $24 \mathrm{~h}$ and reached a maximum level of $0.61 \mathrm{IU} \mathrm{mL} \mathrm{m}^{-1}$ at $24 \mathrm{~h}$ during the saccharification. Meanwhile,

Table 1 Composition of pre-treated and untreated rice straw

\begin{tabular}{|c|c|c|c|c|c|c|c|}
\hline \multirow[b]{2}{*}{ Pre-treatment methods } & \multicolumn{3}{|c|}{ Composition $^{a}(\%)$} & \multirow[b]{2}{*}{ Holocellulose yield $^{b}(\%)$} & \multicolumn{3}{|c|}{ Removal yield $^{c}(\%)$} \\
\hline & Cellulose & Hemicellulose & Lignin & & Cellulose & Hemicellulose & Lignin \\
\hline Untreated & $50.4 \pm 3.3$ & $28.7 \pm 1.9$ & $19.9 \pm 2.2$ & - & - & - & - \\
\hline $\mathrm{Fe}^{3+}+\mathrm{H}_{2} \mathrm{O}_{2}+$ citric acid & $66.2 \pm 6.1$ & $20.1 \pm 2.5$ & $13.7 \pm 4.1$ & $84.9 \pm 5.7$ & $10 \pm 2.4$ & $21.4 \pm 6.3$ & $52.7 \pm 11.2$ \\
\hline $\mathrm{Fe}^{3+}+\mathrm{H}_{2} \mathrm{O}_{2}^{d}$ & $52.7 \pm 7.2$ & $19.2 \pm 3.9$ & $20.8 \pm 4.1$ & $88.9 \pm 6.8$ & $6.1 \pm 1.8$ & $17.2 \pm 5.2$ & $6.7 \pm 2.3$ \\
\hline
\end{tabular}

${ }^{a}$ Composition is shown as percentage of the solid fraction before and after pre-treatment. ${ }^{b}$ Holocellulose yield is shown as percentage of the initial amount of holocellulose. ${ }^{c}$ Removal yield is shown as percentage of the amount in the initial material. ${ }^{d}$ The pre-treatment was performed at pH 6 and $25{ }^{\circ} \mathrm{C}$ for $24 \mathrm{~h}$.
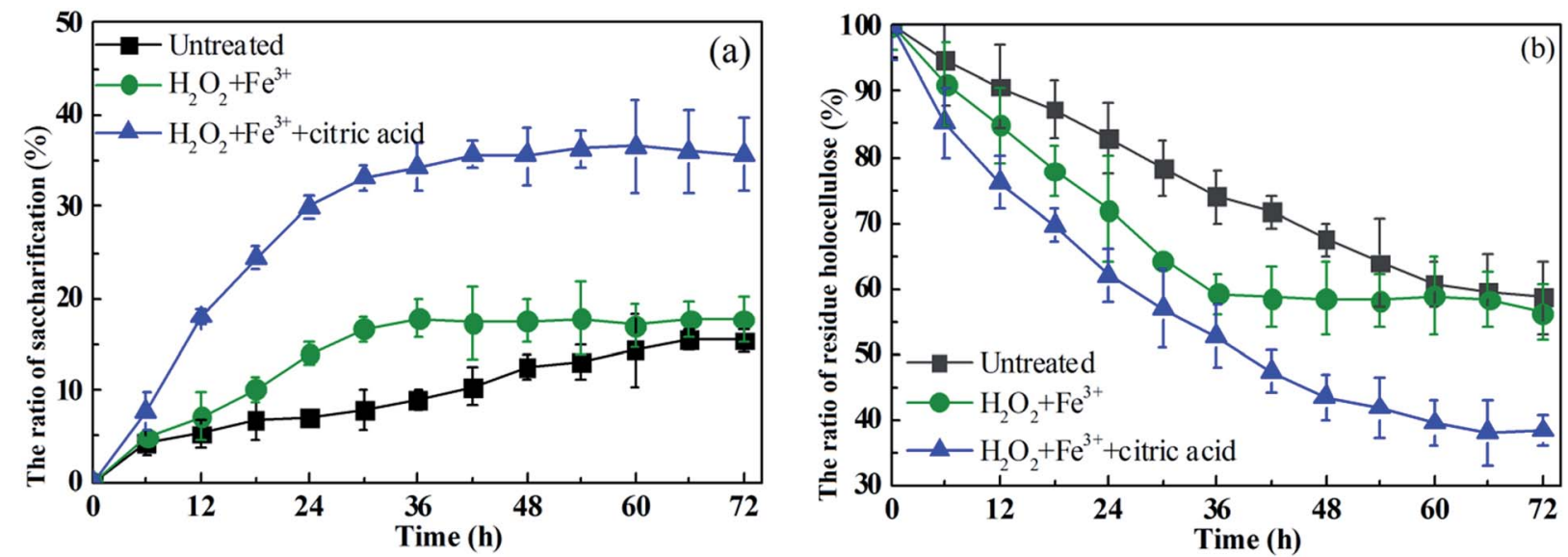

Fig. 8 Time curve of the ratio of rice straw saccharification (a), and the ratio of residue holocellulose (b), of pre-treated/untreated rice straw during saccharification. 
the peak of the $\beta$-glucosidase activity of $\mathrm{Fe}^{3+} / \mathrm{H}_{2} \mathrm{O}_{2}$ pre-treated rice straw $\left(0.42 \mathrm{IU} \mathrm{mL}^{-1}\right)$ and untreated rice straw (0.33 IU $\mathrm{mL}^{-1}$ ) was obtained at $30 \mathrm{~h}$ and $36 \mathrm{~h}$, respectively. In contrast to the $\beta$-glucosidase activity, the activity of endoglucanase and exoglucanase did not exhibit significant difference with time of treatment. The peak of endoglucanase and exoglucanase were both obtained at $\sim 36 \mathrm{~h}$, and the maximum activity of the two was similar. The trend of xylanase activity showed a little difference compared with that of cellulase. The peak activity of xylanase obtained from rice straw pre-treated with $\mathrm{Fe}^{3+} / \mathrm{H}_{2} \mathrm{O}_{2} /$ citric acid or $\mathrm{Fe}^{3+} / \mathrm{H}_{2} \mathrm{O}_{2}$, and untreated rice straw, was at $(36,48$, and 54) h, respectively. Nevertheless, the maximum xylanase activity was similar. The main type of cellulase secreted by $R$. thermocellum M3 ( $\beta$-glucosidase), was compared in the untreated rice straw and the $\mathrm{Fe}^{3+} / \mathrm{H}_{2} \mathrm{O}_{2}$ pre-treated straw. The addition of citric acid not only promoted the maximum $\beta$ glucosidase activity but also shortened the time of $\beta$-glucosidase synthesis. The rice straw pretreated with $\mathrm{Fe}^{3+} / \mathrm{H}_{2} \mathrm{O}_{2} /$ citric acid had a looser structure and more cellulose exposed to microorganisms, which was induced by the cellulose. This explained the relatively high $\beta$-glucosidase activity observed in the saccharification of rice straw pre-treated with $\mathrm{Fe}^{3+} / \mathrm{H}_{2} \mathrm{O}_{2} /$ citric acid. A greater amount of $\beta$-glucosidase was obtained in the rice straw pre-treated with $\mathrm{Fe}^{3+} / \mathrm{H}_{2} \mathrm{O}_{2} /$ citric acid. This may provide an important explanation for why a high relative saccharification ratio was obtained in the $\mathrm{Fe}^{3+} / \mathrm{H}_{2} \mathrm{O}_{2}$ /citric acid pretreated rice straw.

\section{Characteristics of Fenton pretreated rice straw saccharification}

As shown in Table 1, 52.7\% of the lignin content was removed by $\mathrm{Fe}^{3+} / \mathrm{H}_{2} \mathrm{O}_{2} /$ citric acid pre-treatment of rice straw compared to the control (untreated rice straw), whereas only $15.1 \%$ of holocellulose was lost. After pre-treatment with $\mathrm{Fe}^{3+} / \mathrm{H}_{2} \mathrm{O}_{2} /$ citric acid, nearly $85 \%$ of the cellulose and hemicellulose in cornstalks were suitable and available for subsequent fermentation. However, only a small amount of lignin removal $(<10 \%)$ was done using $\mathrm{Fe}^{3+} / \mathrm{H}_{2} \mathrm{O}_{2}$ pre-treatment at the same $\mathrm{pH}$ (i.e., 6), when reduction of holocellulose, cellulose, and hemicellulose was $(11.1,10.0$, and 17.2$) \%$, respectively.

As mentioned before, citric acid was an effective chelator for the degradation of lignin and reduction of the crystallinity of rice straw in the Fenton reaction at $\mathrm{pH}$ 6. This was significant in achieving the aim of lignocellulose pre-treatment, that is, to obtain valuable products like fermentable oligosaccharides, hydrogen, and ethanol. Therefore, the saccharification of pretreated rice straw was tested. The saccharification tests were performed using the candidate strain $R$. thermocellum M3 isolated by Sheng et $a .^{22}$

It can be seen from Fig. 8a that the saccharification result for $\mathrm{Fe}^{3+} / \mathrm{H}_{2} \mathrm{O}_{2}$ pre-treated rice straw is close to that for untreated rice straw. However, the saccharification rate of rice straw pretreated with $\mathrm{Fe}^{3+} / \mathrm{H}_{2} \mathrm{O}_{2}$ is higher than for the untreated rice straw. With the $\mathrm{Fe}^{3+} / \mathrm{H}_{2} \mathrm{O}_{2}$ pre-treated straw as substrate, about $13.3 \%$ of the saccharification accomplished, occurred in $24 \mathrm{~h}$, whereas, within the same time, the saccharification of untreated rice straw was $7.1 \%$. Although the $\mathrm{Fe}^{3+} / \mathrm{H}_{2} \mathrm{O}_{2}$ treated and untreated rice straw were similar in crystallinity, the lignin and hemicellulose content of $\mathrm{Fe}^{3+} / \mathrm{H}_{2} \mathrm{O}_{2}$ treated rice straw was lower than for the untreated straw. Moreover, as mentioned before, the amount of $\beta$-glucosidase obtained during saccharification of rice straw pre-treated with $\mathrm{Fe}^{3+} / \mathrm{H}_{2} \mathrm{O}_{2}$ was greater than for untreated rice straw. This might be the reason for the high saccharification ratio obtained for rice straw pre-treated with $\mathrm{Fe}^{3+} / \mathrm{H}_{2} \mathrm{O}_{2}$. Much higher saccharification was obtained for $\mathrm{Fe}^{3+} / \mathrm{H}_{2} \mathrm{O}_{2} /$ citric acid pre-treated straw, and about $29.9 \%$ of the saccharification was accomplished within $24 \mathrm{~h}$. This result
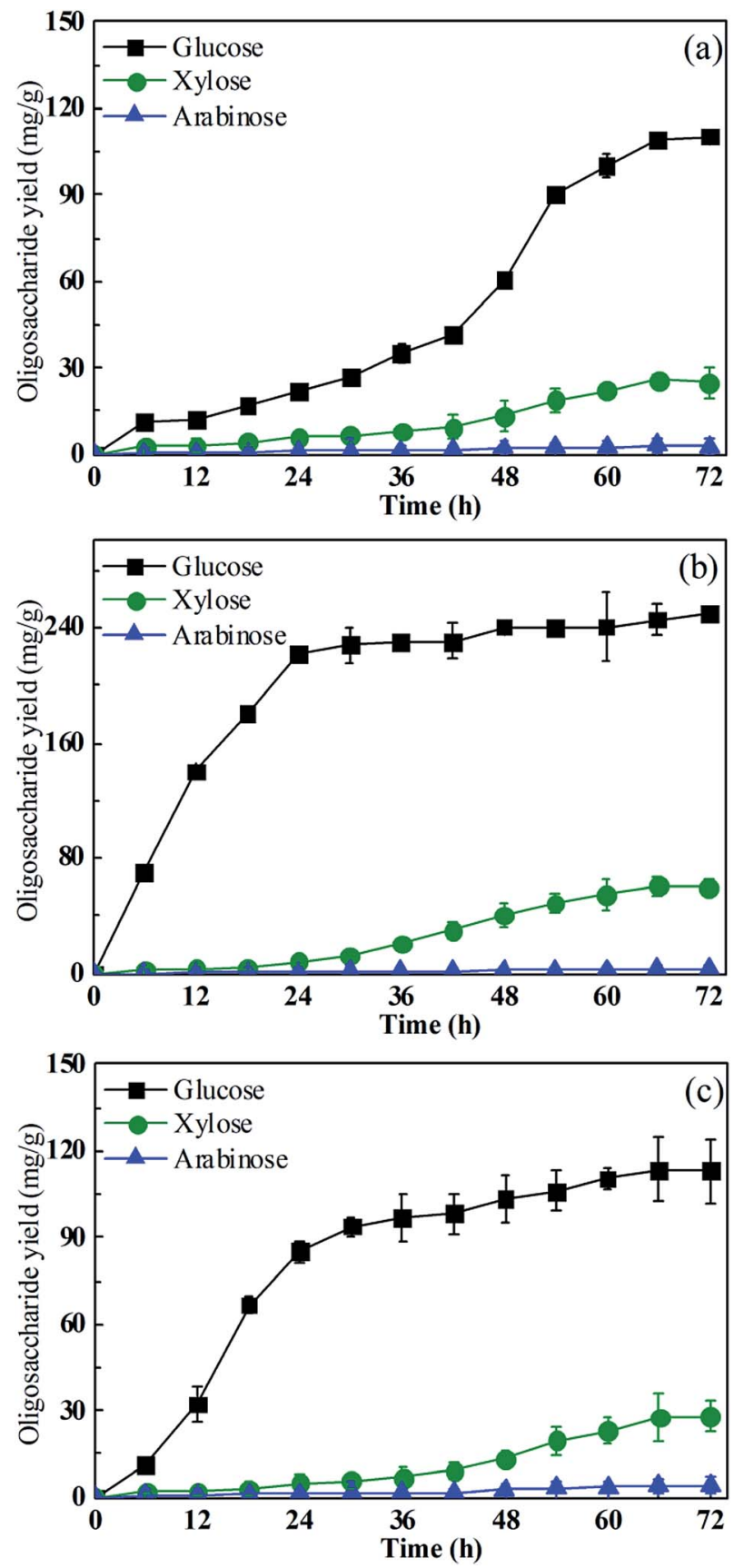

Fig. 9 Type of oligosaccharide yield by pre-treated/untreated rice straw during saccharification. 
indicated that the citric acid not only increased saccharification but also promoted a higher rate of saccharification. Compared with the untreated rice straw and the straw pre-treated with $\mathrm{Fe}^{3+} / \mathrm{H}_{2} \mathrm{O}_{2}$, the rice straw pre-treated with $\mathrm{Fe}^{3+} / \mathrm{H}_{2} \mathrm{O}_{2} /$ citric acid was lower in crystallinity index, lower in lignin content, and higher in $\beta$-glucosidase, which might also contribute to enhanced saccharification.

It was indicated that strain $\mathrm{M} 3$ displayed the most effective utilization of $\mathrm{Fe}^{3+} / \mathrm{H}_{2} \mathrm{O}_{2} /$ citric acid pre-treated rice straw at $\mathrm{pH}$ 6, which resulted in more than $60 \%$ degradation of cornstalk after $72 \mathrm{~h}$ fermentation (Fig. 8b). Compared with straw pretreated with $\mathrm{Fe}^{3+} / \mathrm{H}_{2} \mathrm{O}_{2}$, or untreated rice straw, a saccharification ratio 2 times higher was promoted. The holocellulose utilization exhibited a trend similar to that of the saccharification. More than $60 \%$ of the holocellulose was utilized in the sample pretreated with $\mathrm{Fe}^{3+} / \mathrm{H}_{2} \mathrm{O}_{2} /$ citric acid, while, only $25 \%$ was utilized in the $\mathrm{Fe}^{3+} / \mathrm{H}_{2} \mathrm{O}_{2}$ pre-treated rice straw and untreated rice straw.

The type of oligosaccharides yielded by $\mathrm{Fe}^{3+} / \mathrm{H}_{2} \mathrm{O}_{2} /$ citric acid, $\mathrm{Fe}^{3+} / \mathrm{H}_{2} \mathrm{O}_{2}$, and untreated rice straw are shown in Fig. 9. This indicates that the main oligosaccharide yielded by pre-treated or untreated rice straw was glucose, followed by xylose, accompanied by a trace of arabinose. The maximum glucose yield was obtained from rice straw pre-treated with $\mathrm{Fe}^{3+} / \mathrm{H}_{2} \mathrm{O}_{2} /$ citric acid. The maximum glucose yield was $251.4 \mathrm{mg} \mathrm{L}^{-1}$, and the glucose obtained from the untreated rice straw and $\mathrm{Fe}^{3+} /$ $\mathrm{H}_{2} \mathrm{O}_{2}$ pre-treated straw was $110.4 \mathrm{mg} \mathrm{L}^{-1}$ and $113.4 \mathrm{mg} \mathrm{L}^{-1}$, respectively. The citric acid added to the Fenton reagent promoted the glucose yield, but the xylose and arabinose yield were almost the same for straw pre-treated with $\mathrm{Fe}^{3+} / \mathrm{H}_{2} \mathrm{O}_{2} /$ citric acid and $\mathrm{Fe}^{3+} / \mathrm{H}_{2} \mathrm{O}_{2}$, as well as for the untreated rice straw. That is attributed to the preferential degradation by the Fenton reagent combined with citric acid of hemicellulose over cellulose, which led to greater consumption of xylose.

\section{Conclusions}

This study demonstrated that Fenton pre-treatment of rice straw with citric acid as an iron chelate reagent could enhance saccharification effectively. Citric acid had a profound effect on the Fenton process in terms of boosting the generation of $\mathrm{Fe}^{2+}$, decreasing the consumption of holocellulose by hydroxyl radicals during pretreatment, and maintaining oxidation during the Fenton reaction at near neutral pH. Meanwhile, the addition of citric acid reduced the crystallinity of rice straw, promoted the activity of cellulase and xylanase secreted by $R$. thermocellum M3 during saccharification; and hence, resulted in a greater sugar yield for subsequent bioenergy production. The study demonstrated a highly efficient and environmentally friendly pretreatment method that shows great potential for application in industry.

\section{Acknowledgements}

This research was supported by the National Science Foundation for Distinguished Young Scholars (Grant No. 51225802) and Youth Innovation Promotion Association CAS (2017062).

\section{References}

1 Z.-F. Lei, J.-Y. Chen, Z.-Y. Zhang and N. Sugiura, Bioresour. Technol., 2010, 101, 4343-4348.

2 L. Zhao, G.-L. Cao, A.-J. Wang, H.-Y. Ren, D. Dong, Z.-N. Liu, X.-Y. Guan, C.-J. Xu and N.-Q. Ren, Bioresour. Technol., 2012, 114, 365-369.

3 J. S. Bak, J. K. Ko, I. G. Choi, Y. C. Park, J. H. Seo and K. H. Kim, Biotechnol. Bioeng., 2009, 104, 471-482.

4 M. J. Taherzadeh and C. Niklasson, ACS Symp. Ser., 2004, 3, 49-68.

5 S. Ye and J. Cheng, Bioresour. Technol., 2002, 83, 1.

6 S. H. Mood, A. H. Golfeshan, M. Tabatabaei, G. S. Jouzani, G. H. Najafi, M. Gholami and M. Ardjmand, Renewable Sustainable Energy Rev., 2014, 27, 77-93.

7 A. I. Hatakka, Appl. Microbiol. Biotechnol., 1983, 18, 350-357. 8 Y. H. Jung, H. K. Kim, H. M. Park, Y.-C. Park, K. Park, J.-H. Seo and K. H. Kim, Bioresour. Technol., 2015, 179, 467-472.

9 S. W. Seo and S. H. Kong, Korea Science, 2006, 11(6), 76-82. 10 A. H. Kaksonen and M. L. Riekkola, Water Res., 2003, 37, 255-266.

11 G. Jiang, J. Sun, K. R. Sharma and Z. Yuan, Curr. Opin. Biotechnol., 2015, 33, 192-197.

12 S.-P. Sun, X. Zeng, C. Li and A. T. Lemley, Chem. Eng. J., 2014, 244, 44-49.

13 X. Tao, J. Su, L. Wang and J. F. Chen, J. Mol. Catal. A: Chem., 2008, 280, 186-193.

14 J. J. Pignatello, E. Oliveros and A. MacKay, Crit. Rev. Environ. Sci. Technol., 2006, 36, 1-84.

15 G. Subramanian and G. Madras, Water Res., 2016, 104, 168177.

16 K. Pirkanniemi, S. Metsärinne and M. Sillanpää, J. Hazard. Mater., 2007, 147, 556-561.

17 G. Tachiev, J. A. Roth and A. R. Bowers, Int. J. Chem. Kinet., 2000, 32, 24-35.

18 M. Silva, A. Trovó and R. Nogueira, J. Photochem. Photobiol., A, 2007, 191, 187-192.

19 H. B. Abrahamson, A. B. Rezvani and J. G. Brushmiller, Inorg. Chim. Acta, 1994, 226, 117-127.

20 M. R. Silva, W. Vilegas, M. V. Zanoni and R. F. Pupo Nogueira, Water Res., 2010, 44, 3745-3753.

21 Y. Sun and J. J. Pignatello, J. Agric. Food Chem., 1992, 40, 7481.

22 T. Sheng, L. Zhao, L. F. Gao, W. Z. Liu, M. H. Cui, Z. C. Guo, X. D. Ma, S. H. Ho and A. J. Wang, Biotechnol. Biofuels, 2016, 9, DOI: 10.1186/s13068-016-0585-z.

23 T. Sheng, L. Gao, L. Zhao, W. Liu and A. Wang, RSC Adv., 2015, 5, 99781-99788.

24 A. Wang, L. Gao, R. Nanqi, X. Jifei, L. Chong, C. Guangli, Y. Hao, L. Wenzong, C. L. Hemme and H. Zhili, Appl. Environ. Microbiol., 2011, 77, 517-523.

25 L. Zhao, G. L. Cao, A. J. Wang, H. Y. Ren, C. J. Xu and N. Q. Ren, GCB Bioenergy, 2013, 5, 591-598.

26 L. Huang, L. Gibbins and C. W. Forsberg, Appl. Environ. Microbiol., 1985, 50, 1043-1047. 
27 H. Fadrus and J. Malý, Analyst, 1975, 100, 549-554.

28 E. Morag, E. A. Bayer and R. Lamed, J. Bacteriol., 1990, 172, 6098-6105.

29 U. Rattanachomsri, S. Tanapongpipat, L. Eurwilaichitr and V. Champreda, J. Biosci. Bioeng., 2009, 107, 488-493.

30 H. Zhao, J. H. Kwak, Z. C. Zhang, H. M. Brown, B. W. Arey and J. E. Holladay, Carbohydr. Polym., 2007, 68, 235-241.

31 P. H. F. Pereira, H. J. C. Voorwald, M. O. H. Cioffi, M. L. C. P. D. Silva, A. M. B. Rego, A. M. Ferraria and M. N. D. Pinho, Cellulose, 2014, 21, 641-652.

32 S. I. Mussatto, M. Fernandes, A. M. F. Milagres and I. C. Roberto, Enzyme Microb. Technol., 2008, 43, 124-129.

33 K. Karimi and M. J. Taherzadeh, Bioresour. Technol., 2016, 203, 348-356.

34 R. Sindhu, M. Kuttiraja, P. Binod, R. K. Sukumaran and A. Pandey, Ind. Crops Prod., 2014, 52, 169-176.

35 K. E. Hammel, A. N. Kapich, K. A. Jensen and Z. C. Ryan, Enzyme Microb. Technol., 2002, 30, 445-453.

36 B. Goodell, Brown-rot fungal degradation of wood: our evolving view, ACS Publications, 2003.

37 L. A. De, R. F. Dantas and S. Esplugas, Water Res., 2014, 61, 232-242.

38 W. Huang, M. Brigante, F. Wu, K. Hanna and G. Mailhot, J. Photochem. Photobiol., A, 2012, 239, 17-23.
39 K. Messner and E. Srebotnik, FEMS Microbiol. Rev., 1994, 13, 351-364.

40 Y. Ohashi, Y. Kan, T. Watanabe, Y. Honda and T. Watanabe, Org. Biomol. Chem., 2007, 5, 840.

41 C. Ruales-Lonfat, J. F. Barona, A. Sienkiewicz, J. Vélez, L. N. Benítez and C. Pulgarín, Appl. Catal., B, 2016, 180, 379-390.

42 W. Li, Q. Liu, Q. Ma, T. Zhang, L. Ma, H. Jameel and H. M. Chang, Bioresour. Technol., 2016, 219, 753-756.

43 D. Song, Y. H. Seo, M. Sung, S. B. Park and J. I. Han, J. Ind. Eng. Chem., 2015, 27, 31-34.

44 E. Evgenidou, I. Konstantinou, K. Fytianos and I. Poulios, Water Res., 2007, 41, 2015-2027.

45 J. M. Friedrich, C. Ponce-De-León, G. W. Reade and F. C. Walsh, J. Electroanal. Chem., 2004, 561, 203-217.

46 K. K. Pandey and A. J. Pitman, J. Polym. Sci., Part A: Polym. Chem., 2004, 42, 2340-2346.

47 J. S. Van Dyk and B. I. Pletschke, Biotechnol. Adv., 2012, 30, 1458-1480.

48 Y. Tianxue, Y. Li, H. Haobo, X. Beidou, H. Liansheng, W. Xiaowei, H. Caihong, W. Kun, Z. Ying and C. Bin, Bioresour. Technol., 2014, 163, 356-359.

49 H. Xu, G. Yu, X. Mu, C. Zhang, P. Deroussel, C. Liu, B. Li and H. Wang, Ind. Crops Prod., 2015, 76, 638-646. 